had a history of hepatitis; and, secondly, in the three cases of infection not transmitted by transfusion all the donors were negative for hepatitis $B$ core antibody.

Blood donations are accepted by the National Blood Transfusion Service 12 months after an episode of jaundice or hepatitis in the donor so long as testing for hepatitis B surface antigen yields negative results. In the light of our findings and recent legislation relating to product liability we believe that this policy should be reassessed and that consideration should be given to testing such donors for hepatitis B core antibody and excluding them if they are found to be positive.

I Barbara JA. Microbiology in blood transfusion. London: Wright, 1983.

2 Menitove JE. Rationale for surrogate testing to detect non A non B hepatitis. Transfusion Medicine Review 1988;2:65-75.

3 Hoffnagle JH, Seeff LB, Bales ZB, Zimmerman HJ, and the Veterans Administration Hepatitis Cooperative Study. Type B hepatitis after transfusion with blood containing antibody to hepatitis B core antigen. N Engl f Med 1978;298:1379-83.

4 Cossart YE, Kirsch S, Ismay SL. Post transfusion hepatitis in Australia. Lancet 1982;i:208-13.

(Accepted 3I May 1989)

\section{Surgical footwear: a survey of prescribing consultants}

\author{
M Lord, J Foulston
}

Department of Mechanical Engineering, University College London, London WC1E 7JE

M Lord, MPHIL, lecturer

Department of Medical

Engineering and Physics,

King's College School of

Medicine and Dentistry,

Dulwich Hospital, London

SE22 8PT

J Foulston, MCHS, honorary

research fellow

Correspondence to:

Ms Lord.

BrMed J 1989;299:657 rheumatology and rehabilitation.
Changes are likely to occur in the present system by which patients obtain special footwear because of alterations in contractual aspects and the introduction of new technology such as digital shape capture and computerised design. ${ }^{12}$ Continuous, central records are not kept on the provision of footwear, though we have conservatively estimated that costs across the United Kingdom in 1986 were about $£ 12$ million. As a basis for the introduction of technological changes more information on the present system would be advantageous. Previous surveys have concentrated on the views of consumers. ${ }^{3+}$ We present a report on a survey into the system of supplying footwear from the point of view of most consultants in the United Kingdom who prescribe and accept the footwearnamely, those in diabetology, orthopaedics, and

\section{Methods and results}

A questionnaire requested background information about type of clinics, the current organisation of the delivery service, delegation in an ideal world, and respondents' perception of aspects of the service. We sent out 1696 questionnaires and $821(48.4 \%)$ were returned, response rates being 176/430 (40.9\%), $469 / 983(47 \cdot 7 \%)$, and $176 / 283(62 \cdot 2 \%)$ for diabetologists, orthopaedic surgeons, and rheumatologists respectively; 285 respondents volunteered written comments.

Many written comments emphasised dissatisfaction with the speed of delivery (table) with further indications on the desirability of a permanent workshop within the hospital or more frequent visits by fitters. With traditional methods of production this probably cannot be much improved. Even when factories meet the suggested maximum turn around time of six weeks from receipt of cast or measures to dispatch for trial fitting the overall supply time is probably too long by clinical criteria. The growing awareness of the availability of stock orthopaedic shoes may influence the future pattern of prescription. Use of off the shelf shoes of extra depth circumvents delays in fitting and provides a cheaper and more cosmetically acceptable alternative. Over a fifth of all consultants were dissatisfied with the suitability of the footwear (table). In addition, the cosmesis of surgical shoes was sometimes seen as poor. Some consultants suggested that free shoes may lead to abuse of the system and that a nominal charge should be made. The relationship between the consultant and fitter or patient and fitter was often commented on; many thought that a close relationship was needed. A general frustration with both logistic and training aspects was evident. There was evidence that financial pressures may be detrimental. The best contractor is sometimes the most expensive, and a change of contractoroften not necessarily in the patients' best interest - is occasionally initiated by restrictions on costs.

Responses to questions "Are you generally satisfied that footwear is suitable in practice for the purpose for which it is prescribed?" and "Are you generally satisfied with the speed of production of footwear?"

\begin{tabular}{lcr}
\hline & \multicolumn{2}{c}{ No (\%) of consultants satisfied with: } \\
\cline { 2 - 3 } Specialty & Suitability & \multicolumn{1}{c}{ Speed } \\
\hline Diabetology & $123 / 171(72)$ & $81 / 120(48)$ \\
Orthopaedics & $368 / 464(79)$ & $251 / 462(54)$ \\
Rheumatology and rehabilitation & $123 / 176(70)$ & $69 / 176(39)$ \\
\hline
\end{tabular}

Chiropodists play an important part in supplying footwear for diabetic patients, and diabetologists reported closer links with chiropodists than did other groups of consultants. Analysis of the data showed considerable geographical variations. Under a third of consultants were satisfied with speed in North West Thames compared with two thirds in the Northern region. Satisfaction with suitability varied from just over half in North West Thames to nearly complete in the Northern region.

\section{Comment}

With the event of clinical accounting in NHS hospitals consultants' requirements for the supply of footwear will become even more important in determining the contractor and type of footwear. Consultants have clearly indicated improvements necessary in the supply of surgical footwear, primarily in the speed of delivery, fitting, training of staff, and perhaps, in some cases, rationalisation of the system. Some concern was expressed over changes in contractors because of economic rather than clinical reasons. Under direct budgetary control criteria will tend towards cost-benefit rather than cost or benefit alone.

We thank the Department of Health and Social Security's supply division for financial support; Drs Arnold Bloom and Frank Dudley Hart and Professor Leslie Klenerman; Dr M Leaning, of the operational research unit, University College London, for help with analysis; and the consultants who took part in the survey. Copies of the full report may be obtained from $M L$.

1 Jones D. Impact of advanced manufacturing technology on prosthetic and orthotic practice. $\mathcal{F}$ Biomed Eng 1988;10:179-83.

2 Lord $M$, Jones $\mathrm{D}$. Issues and themes in computer aided design for external prosthetics and orthotics. $\mathcal{F}$ Biomed Eng 1988;10:491-8.

Office of Population Censuses and Surveys. National Health Service surgical footwear. A study of patient satisfaction. London: HMSO, 1979

4 Guthrie D. A future for the orthotic service: a report by the working party on the availability and supply of orthotic appliances. London: Royal Assuciation for availability and supply of orthotic appliances. London: Royal Association for
Disability and Rehabilitation, 1983 . (Accepted 26 June 1989) 